\title{
Cancer stem-like sphere cells induced from de-differentiated hepatocellular carcinoma-derived cell lines possess the resistance to anti-cancer drugs
}

Noriaki Hashimoto, Ryouichi Tsunedomi, Kiyoshi Yoshimura, Yusaku Watanabe, Shoichi Hazama and Masaaki Oka

\begin{abstract}
Background: Cancer stem cells (CSCs) are thought to play important roles in therapy-resistance. In this study, we induced cancer stem-like cells from hepatocellular carcinoma (HCC) cell lines using a unique medium, and examined their potential for resistance to anti-cancer drugs.

Methods: The human HCC cell lines SK-HEP-1 (SK), HLE, Hep 3B, and HuH-7 were used to induce cancer stem-like cells with our sphere induction medium supplemented with neural survival factor-1. NANOG and LIN28A were examined as stemness markers. Several surface markers for CSC such as CD24, CD44, CD44 variant, and CD90 were analyzed by flow-cytometry. To assess the resistance to anti-cancer drugs, the MTS assay, cell cycle analysis, and reactive oxygen species (ROS) activity assay were performed.

Results: Poorly differentiated HCC derived SK and undifferentiated HCC derived HLE cell lines efficiently formed spheres of cells (SK-sphere and HLE-sphere), but well-differentiated HCC-derived HuH-7 and Hep 3B cells did not. SK-spheres showed increased NANOG, LIN28A, and ALDH1A1 mRNA levels compared to parental cells. We observed more CD44 variant-positive cells in SK-spheres than in parental cells. The cell viability of SK-spheres was significantly higher than that of SK cells in the presence of several anti-cancer drugs except sorafenib (1.7- to 7.3-fold, each $P<0.05)$. The cell cycle of SK-spheres was arrested at the G0/G1 phase compared to SK cells. SK-spheres showed higher ABCG2 and HIF1A mRNA expression and lower ROS production compared to parental cells.
\end{abstract}

Conclusion: Our novel method successfully induced cancer stem-like cells, which possessed chemoresistance that was related to the cell cycle, drug efflux, and ROS.

Keywords: Cancer stem cell, HCC, Sphere, Chemoresistance

\section{Background}

Hepatocellular carcinoma (HCC) is the sixth most common and the third most deadly cancer worldwide affecting 1 million individuals annually [1]. Most potentially curative therapies for HCC such as surgical resection, transplantation and ablation therapy are of limited efficacy in advanced stages, and the recurrence rate after these treatments is 40 to $80 \%$ within 5 years [2,3]. Various types of post-operative therapies, including transarterial lipiodol

\footnotetext{
* Correspondence: tsune-r@yamaguchi-u.ac.jp

Department of Digestive Surgery and Surgical Oncology, Yamaguchi University Graduate School of Medicine, 1-1-1 Minami-Kogushi, Ube, Yamaguchi 755-8505, Japan
}

chemoembolization, systemic or focal chemotherapy, $\alpha-$ interferon, adoptive immunotherapy, and oral acyclic retinoid acid have been used in HCC patients following curative treatment. However, the benefits of adjuvant therapy have not been definitively demonstrated. Therefore, new adequate adjuvant therapy is needed to improve survival.

Recent research has focused on cancer stem cells (CSCs) to increase our understanding of the characteristics of cancers including HCC. CSCs possess stem cell properties such as a self-renewal capacity, tumor-initiating ability, higher tumorigenicity, metastatic potential, and chemoresistance [4]. To investigate CSC properties such as tumor initiation and recurrence, many studies have examined methods for 
isolation of CSCs from cancer specimens or cell lines. As a result, a side-population of cells and several proteins as markers for CSCs have been identified [5,6]. These CSC markers include CD44, CD133, CD90, CD13, aldehyde dehydrogenase (ALDH), oval cell marker OV6, and epithelial cell adhesion molecule [7-14]. However, resulting yields of CSCs have been too low for further analysis [15]. Alternatively, as a functional approach, enrichment of a potential CSC subpopulation using sphere formation with a conditioned serum-free culture system supplemented with epidermal growth factor (EGF) and basic fibroblast growth factor (bFGF) was considered useful for enriching CSCs. Sphere cells possess the capacity for self-renewal and tumorigenicity and are thus considered to be CSCs $[16,17]$.

Initially, CSCs and their progenitor cancer cells were thought to form a unidirectional hierarchy, with CSCs located at the top of the hierarchy [18]. Consistent with the hierarchy model, isolation of CSCs has mainly been performed with well-differentiated HCC cell lines, which are thought to include relatively large quantity of CSCs compared to cell lines derived from advanced HCC $[17,19-22]$. On the other hand, recent breast cancer studies have revealed the plasticity of cancer cells in which differentiated cancer cells can transform to attain cancer stem-like properties via epithelial-mesenchymal transition (EMT) [23]. Moreover, higher grade glioma or oral squamous cell carcinoma cells can form a sphere of cells with higher CSC marker expression compared to lower grade cancers $[24,25]$. Regarding HCC, previous studies have focused on the isolation of CSCs from less advanced HCC. In this study, based on the concept of cancer plasticity, we tried to induce CSCs from cell lines derived from advanced HCC using a unique sphere induction medium.

\section{Methods}

\section{Cell lines}

The human HCC cell lines SK-HEP-1 (SK), HLE, HuH-7, and Hep 3B were purchased from the Health Science Research Resources Bank (Osaka, Japan) and American Type Culture Collection (Rockville, MD). The SK and HLE cell lines are poorly differentiated and undifferentiated HCC derivatives, respectively. The $\mathrm{HuH}-7$ and Hep 3B cell lines are well-differentiated HCC derivatives. Cells were cultured in DMEM (Nissui Pharmaceutical, Tokyo, Japan) with $10 \%$ heat-inactivated fetal bovine serum (FBS, Life Technologies, Tokyo, Japan) supplemented with penicillin $(100 \mathrm{U} / \mathrm{mL})$, streptomycin $(100 \mu \mathrm{g} / \mathrm{mL})$, and sodium bicarbonate $(1.5 \mathrm{~g} / \mathrm{L})$ at $37^{\circ} \mathrm{C}$ in a humidified atmosphere of $5 \% \mathrm{CO}_{2}$ in air.

\section{Induction of sphere cells}

Cells were suspended in the sphere induction medium, which is based on neural stem cell medium. The basal medium for the sphere induction medium is DMEM/F12
(Sigma-Aldrich, Tokyo, Japan) supplemented with $10 \mathrm{mM}$ HEPES (Sigma-Aldrich), $1 \times$ antibiotic-antimycotic solution (Sigma-Aldrich), 0.6\% glucose (Sigma-Aldrich), $1 \mathrm{mg} / \mathrm{mL}$ transferrin, $250 \mu \mathrm{g} / \mathrm{mL}$ insulin (Sigma-Aldrich), $0.6 \mathrm{mM}$ putrescine (Sigma-Aldrich), $0.3 \mu \mathrm{M}$ sodium selenite (Sigma-Aldrich), and $0.2 \mu \mathrm{M}$ progesterone (Sigma-Aldrich). Complete sphere induction medium was prepared by adding $2 \mu \mathrm{g} / \mathrm{mL}$ heparin (Sigma-Aldrich), $10 \mathrm{ng} / \mathrm{mL}$ human recombinant EGF (Sigma-Aldrich), 10 ng/mL bFGF (Merck Millipore, Tokyo, Japan), $10 \mathrm{ng} / \mathrm{mL}$ leukemia inhibitory factor (LIF, Merck Millipore), $60 \mu \mathrm{g} / \mathrm{mL} N$-acetyl-L-cysteine (NAC, Sigma-Aldrich), and 1/50 vol. neural survival factor1 (NSF-1, Lonza, Tokyo, Japan) to the basal medium. Briefly, cells were collected and washed to remove serum and then cultured in the sphere induction medium at $37^{\circ} \mathrm{C}$ in a humidified atmosphere of $5 \% \mathrm{CO}_{2}$ in air. The next day, induction was begun, and floating cells were transferred into a hydrophilic ultra low attachment flask (Corning, Corning, NY).

\section{Semi-quantitative real-time RT-PCR}

Semi-quantitative real-time PCR (semi-qRT-PCR) was performed as described previously with minor modifications [26]. RT-PCR amplification was performed using LightCycler 480 Probe Master (Roche Diagnostics, Tokyo, Japan) and Universal ProbeLibrary Probes (Roche Diagnostics) in a LightCycler System Version 3 (Roche Diagnostics). Primers and probes are listed in Additional file 1: Table S1. Amplification was performed according to a two-step cycle procedure consisting of 45 cycles of denaturation at $95^{\circ} \mathrm{C}$ for $10 \mathrm{sec}$ and annealing/elongation at $60^{\circ} \mathrm{C}$ for $30 \mathrm{sec}$. We measured mRNA levels semi-quantitatively using the $\Delta / \Delta$ threshold cycle $(\mathrm{Ct})$ method. Both glyceraldehyde-3-phosphate dehydrogenase (GAPDH) and phosphoglycerate kinase 1 (PGK1) were used simultaneously as reference genes. The values are expressed as relative to the SK-HEP-1 cells. Triplicate wells were analyzed in each assay.

\section{Flow cytometry}

After cell cultivation, cells were dissociated with Accumax (Innovative Cell Technologies, San Diego, CA). Dissociated cells were then stained with Fixable Viability Dye eFluor 450 (eBioscience, San Diego, CA) to distinguish between living and dead cells. For flow cytometric analysis, the cells were incubated with the following fluorescence-conjugated antibodies: anti-CD44 APC (eBioscience), anti-CD24 APC (eBioscience), or anti-CD90 FITC (Miltenyi Biotec, Bergisch Gladbach, Germany). Rat IgG2b, k isotype control APC (eBioscience), mouse IgG1 APC isotype control (R\&D Systems), and mouse IgG1 FITC isotype control (R\&D Systems) were used as negative controls, respectively. For CD44 variant staining, anti-CD44v9 (Cosmo Bio, Tokyo, Japan) and mouse anti-rat IgG FITC (eBioscience) were used as primary and secondary antibodies, respectively. Rat 
IgG2a, k Isotype Control (eBioscience) was used as a negative control for the anti-CD44v9 antibody. Flow cytometric analysis was performed using a MACSQuant analyzer (Miltenyi Biotec).

Cell cycle distribution was analyzed with propidium iodide staining followed by flow cytometry. Cells were fixed with $70 \%$ ethanol and then resuspended in PI/RNase Staining Buffer (BD Biosciences, Franklin Lakes, NJ). The DNA content of cells was analyzed using a MACSQuant analyzer.

\section{Cell viability assay}

The CellTiter 96 AQueous One Solution Cell Proliferation Assay (Promega, Tokyo, Japan), which includes 3-(4,5dimethylthiazol-2-yl)-5-(3-carboxymethoxyphenyl)-2-(4sulfophenyl)-2H-tetrazolium, inner salt (MTS) was used according to the manufacturer's instructions for evaluation of cell viability. Briefly, $5 \times 10^{3}$ cells/well were seeded into 96-well plates and cultivated in sphere induction medium for 7 days to induce sphere cells. Then, an equal volume of the same medium or medium containing 5-fluorouracil (5-FU, Sigma-Aldrich), cisplatin (Sigma-Aldrich), carboplatin (Sigma-Aldrich), doxorubicin (Sigma-Aldrich), docetaxel (Sigma-Aldrich), suberoylanilide hydroxamic acid (SAHA, Cosmo Bio), irinotecan hydrochloride (SigmaAldrich), sunitinib malate (Sigma-Aldrich), or sorafenib tosylate (MBL, Nagoya, Japan) was added to the wells and incubated for 24 -hours at $37^{\circ} \mathrm{C}$ in $5 \% \mathrm{CO}_{2}$ in air. After incubation in anti-cancer drugs, MTS was added to the cells, which were then incubated for 2 additional hours at $37^{\circ} \mathrm{C}$. The optical density of the culture medium at 492 and $650 \mathrm{~nm}$ was measured by using an EnVision plate reader (PerkinElmer, Waltham, MA). Triplicate wells were analyzed in each assay.

\section{Measurement of reactive oxygen species (ROS)}

Intracellular ROS generation was measured with an OxiSelect ROS Assay Kit (CELL BIOLABS, San Diego, CA) according to the manufacturer's instructions. The cell membrane-permeable fluorescent dye 2',7'-dichlorofluorescein diacetate (DCFH-DA) was added to cells. DCFHDA is converted to the impermeable nonfluorescent compound DCFH by intracellular esterases. Highly fluorescent DCF is produced by oxidation of DCFH by ROS. The fluorescence intensity of DCF inside the cells was measured using an EnVision plate reader. Triplicate wells were analyzed in each assay.

\section{Statistical analysis}

Each experiment was repeated at least three times, and data are expressed as the mean \pm standard deviations. Data were compared using the Mann-Whitney $U$-test or repeatedmeasures analysis of covariance (ANCOVA), using SPSS Statistics 17.0 software (IBM, Tokyo, Japan). A $P$ value of $<0.05$ was considered statistically significant.

\section{Results}

Induction of sphere cells from HCC cell lines

Four human HCC cell lines, SK, HLE, Hep 3B and $\mathrm{HuH}-7$, were used for induction of sphere cells. SK and HLE cells could form sphere cells (SK-spheres and HLE-spheres) from single cells (Figure 1). SK-spheres formed larger spheroids from single cells than HLEspheres (Figure 1A-D). Sphere formation was more efficient, when starting with a high density of cells: $1 \times 10^{5}$ cells/mL (Figure $1 \mathrm{E}$ and $\mathrm{F}$ ). In the high-density condition, HLE cells formed floating spheroids and some adherent cells (Additional file 2: Figure S1A and B). Therefore, the floating cells were transferred into a hydrophilic culture flask on the next day of the sphere induction. In the hydrophilic flask, SK-spheres formed (Figure 1E), but HLE-spheres formed aggregated spheroids at day 7 (Figure 1F). In addition, SK-sphere and HLE-sphere cells could form spheroids again after dissociation (Additional file 2: Figure S1C and D). When the dissociated SK-sphere and HLE-sphere cells were returned to normal medium containing FBS, adherent cells formed again (Additional file 2: Figure S1E and F). Hep $3 \mathrm{~B}$ and $\mathrm{HuH}-7$ cells formed neither spheroids nor floating cells in these same conditions (Additional file 2: Figure S1G and H). Furthermore, in our sphere induction medium, no sphere cells were induced from SK cells when NSF-1 was not added (Figure 2). Conversely, basal medium supplemented with only NSF-1 could induce sphere cells from SK, although the spheroids obtained were adherent. Hence, de-differentiated HCCderived cell lines, especially the SK cells, could form floating spheroids in our condition supplemented with NSF-1, but well-differentiated HCC-derived cell lines did not. According to these observations, we focused on the SK-sphere cells obtained after 7 days of induction from a high-density cell culture for the following analysis.

\section{Expression of stemness markers}

Our semi-qRT-PCR analysis showed that levels of NANOG and LIN28A mRNA in SK-sphere cells were higher than those in parental SK cells (Figure 3). Furthermore, the SK-sphere cells showed approximately 3-fold higher ALDH activity compared to SK cells (Additional file 3: Figure S2). However, sphere cells derived from HLE cells showed weak upregulation of the NANOG mRNA expression compared to the case of SK and SK-sphere cells (Figure 3A).

\section{Expression of CSC markers}

We examined the expression levels of known CSC markers using flow cytometric analysis. The proportions of positive cells for CD44 standard isoform (CD44s) were higher in the sphere-forming SK and HLE cells than in 


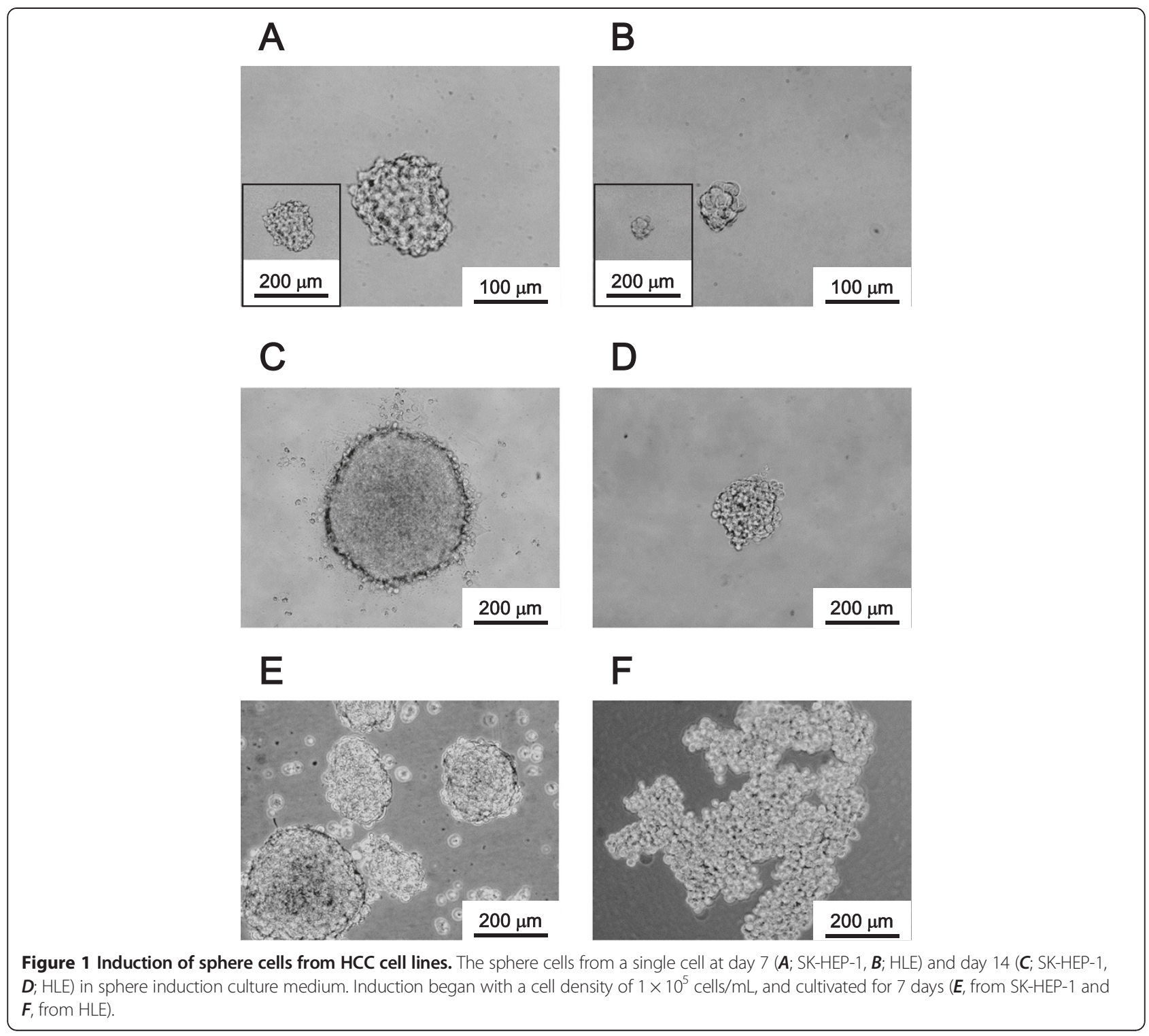

the non-sphere-forming $\mathrm{Hep} 3 \mathrm{~B}$ and $\mathrm{HuH}-7$ cells (Figure 4A). Moreover, the proportions of positive cells for CD44 variant isoform $(\mathrm{CD} 44 \mathrm{v})$ were more than 4.5 -fold higher in the sphere-formed SK-sphere and HLE-sphere cells than parental cells $(P<0.05$, Figure 4B-D). In contrast, CD24- and CD90-positive cells were decreased in sphere-formed cells compared to parental cells (Figure 5A and B). Regarding CD133, nearly all SK and HLE cells were negative for anti-CD133 antibody, and we observed no induction and slight induction of CD133 expression in SK-sphere and HLE-sphere cells, respectively (Figure 5C).

\section{Susceptibility of SK-derived sphere cells to anti-cancer drugs}

The susceptibility of SK and SK-sphere cells to several anticancer drugs was evaluated by measuring the viability of cells treated with anti-cancer drugs for 24 hours (Figure 6). SK-sphere cells showed significantly higher viability in medium containing 5-FU, cisplatin, carboplatin, doxorubicin, docetaxel, SAHA, irinotecan, and sunitinib compared to SK cells (1.7 to 7.3-fold at each of the highest doses, $P<$ 0.05). Interestingly, no significant anti-cancer effect was seen with sorafenib between SK-sphere cells and SK cells (Figure 6I). Similarly, HLE-sphere cells showed increased chemoresistace compared to HLE cells (Figure 7). As a result, both of obtained sphere cells showed tolerance to several types of anti-tumor drugs.

\section{Expression of ATP-binding cassette $(A B C)$ transporters}

Using semi-qRT-PCR and flow cytometry, we measured the mRNA and protein expression levels, respectively, of $\mathrm{ABCG} 2$, which is an $\mathrm{ABC}$ transporter. SK-sphere cells 


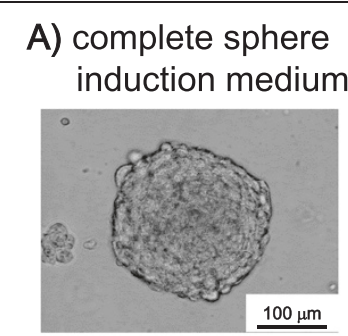

D) without LIF

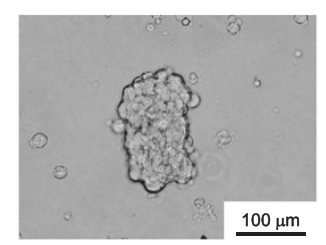

B) without bFGF

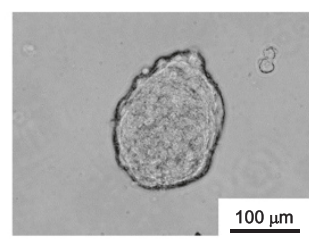

E) without NSF-1

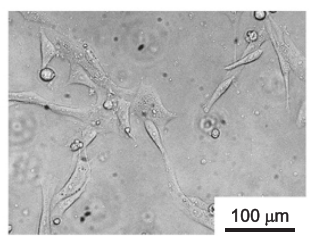

C) without EGF

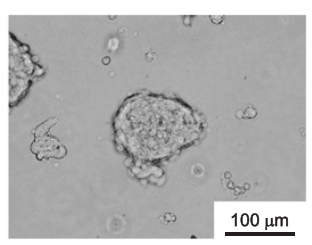

F) basal medium with NSF-1

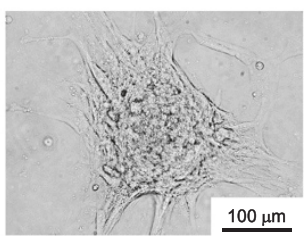

Figure 2 Factors for sphere induction. Sphere induction was performed with a cell density of $1 \times 10^{5}$ SK-HEP-1 cells $/ \mathrm{mL}$ for 7 days.

$\boldsymbol{A}$, complete sphere induction medium was used. $\boldsymbol{B}, \boldsymbol{C}, \boldsymbol{D}$, and $\boldsymbol{E}$, complete induction medium lacking bFGF, EGF, LIF, or NSF-1, respectively, was used. $\boldsymbol{F}$, the basal medium was supplemented with only NSF-1.

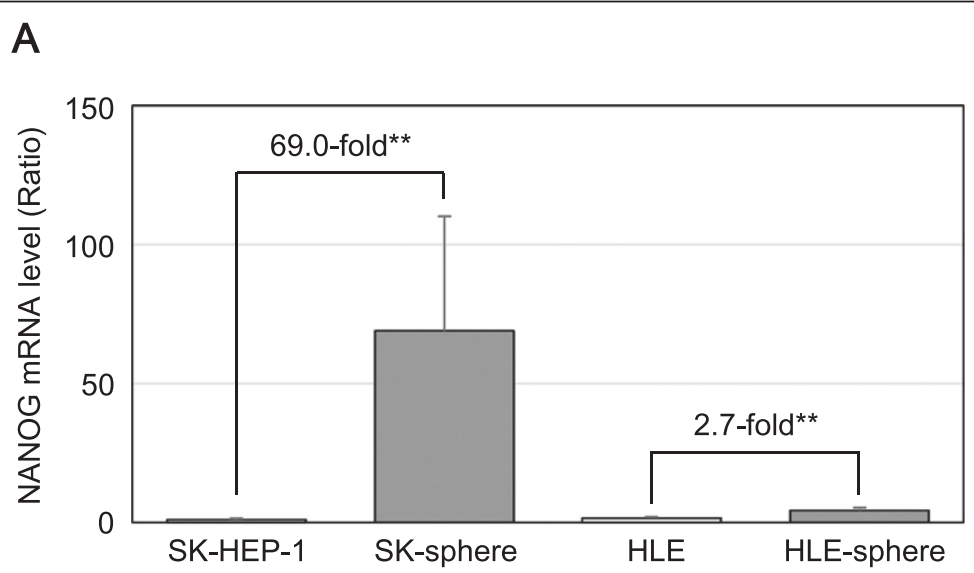

B

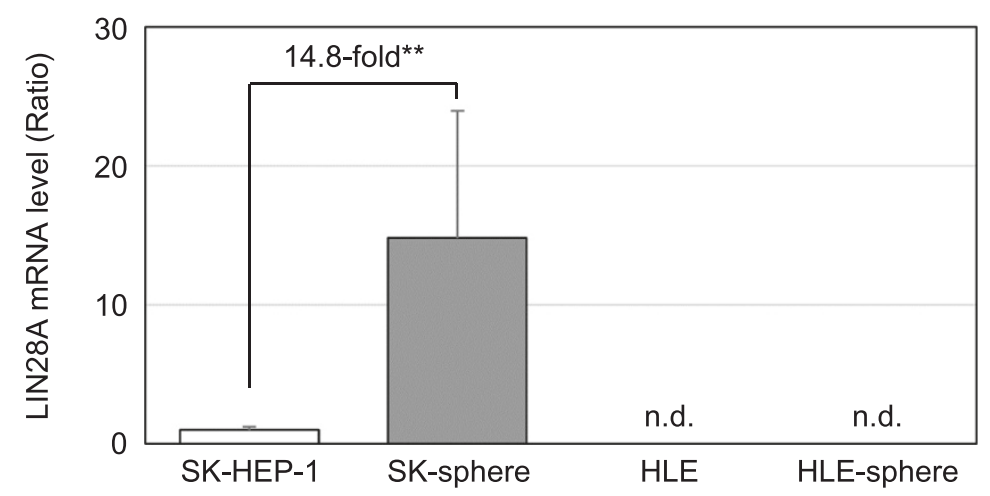

Figure 3 mRNA levels of stemness markers in the induced sphere cells. The mRNA levels of NANOG $(\boldsymbol{A})$ and LIN28A (B) were measured with semi-quantitative RT-PCR and represented as the ratio to levels in SK-HEP-1 cells. ${ }^{* *} P<0.05$ with the Mann-Whitney U-test. n.d., not detectable in our experimental condition. 

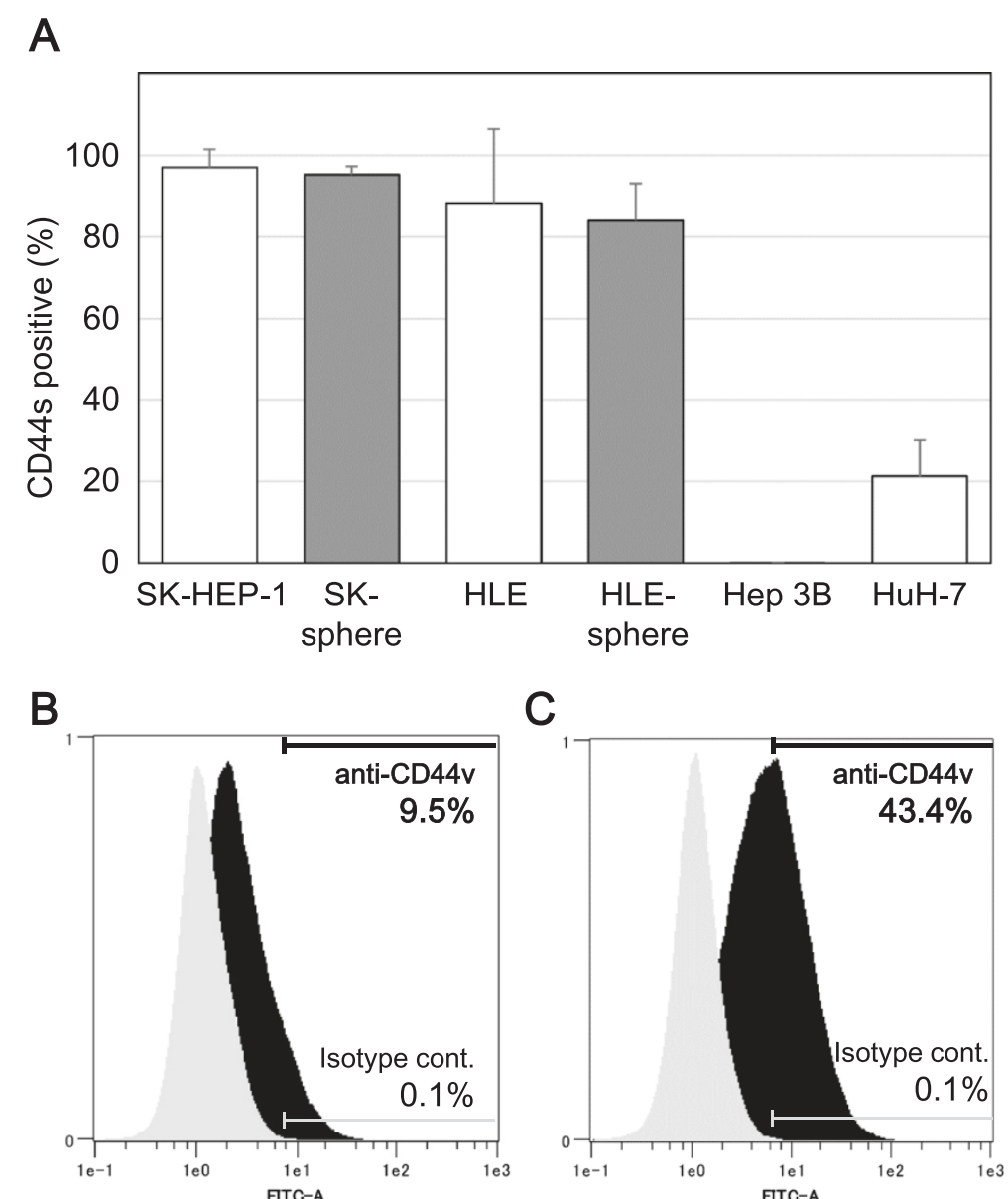

D

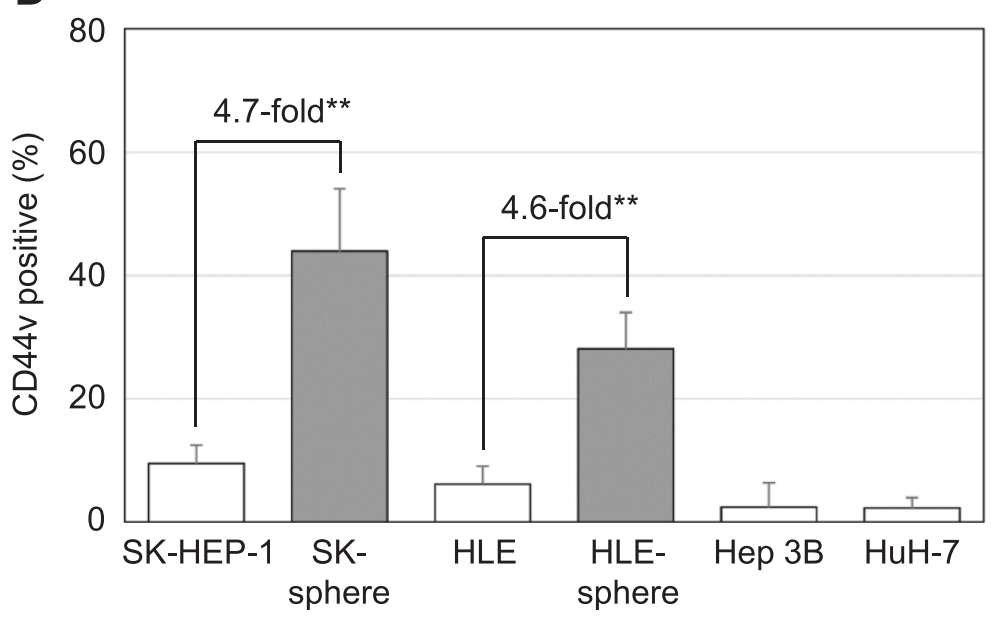

Figure 4 Flow cytometric analysis of CD44 expression. Cells were stained with APC-conjugated anti-CD44 antibody ( $\boldsymbol{A})$ or un-labeled antiCD44 variant antibody followed by FITC-conjugated mouse anti-rat lgG antibody $(\boldsymbol{B}$ to $\boldsymbol{D})$ and then separated with a flow cytometer. The positive for CD44s population in cells with sphere-forming potential, SK-sphere and HLE-sphere, were higher than those in non-sphere-forming cells $(\boldsymbol{A})$. $\boldsymbol{B}$ and $\boldsymbol{C}$, representative flow cytometry histograms of SK-HEP-1 and SK-sphere cells, respectively. Black and gray histograms represent cells stained with anti-CD44v and isotype control antibodies, respectively. $\boldsymbol{D}$, bar-chart summarized from independent flow cytometric experiments. Sphere cells, SK-sphere and HLE-sphere, showed an increased population of CD44V positive cells compared to their parental cells $(\boldsymbol{D})$. ${ }^{* *} P<0.05$ with the Mann-Whitney U-test. 

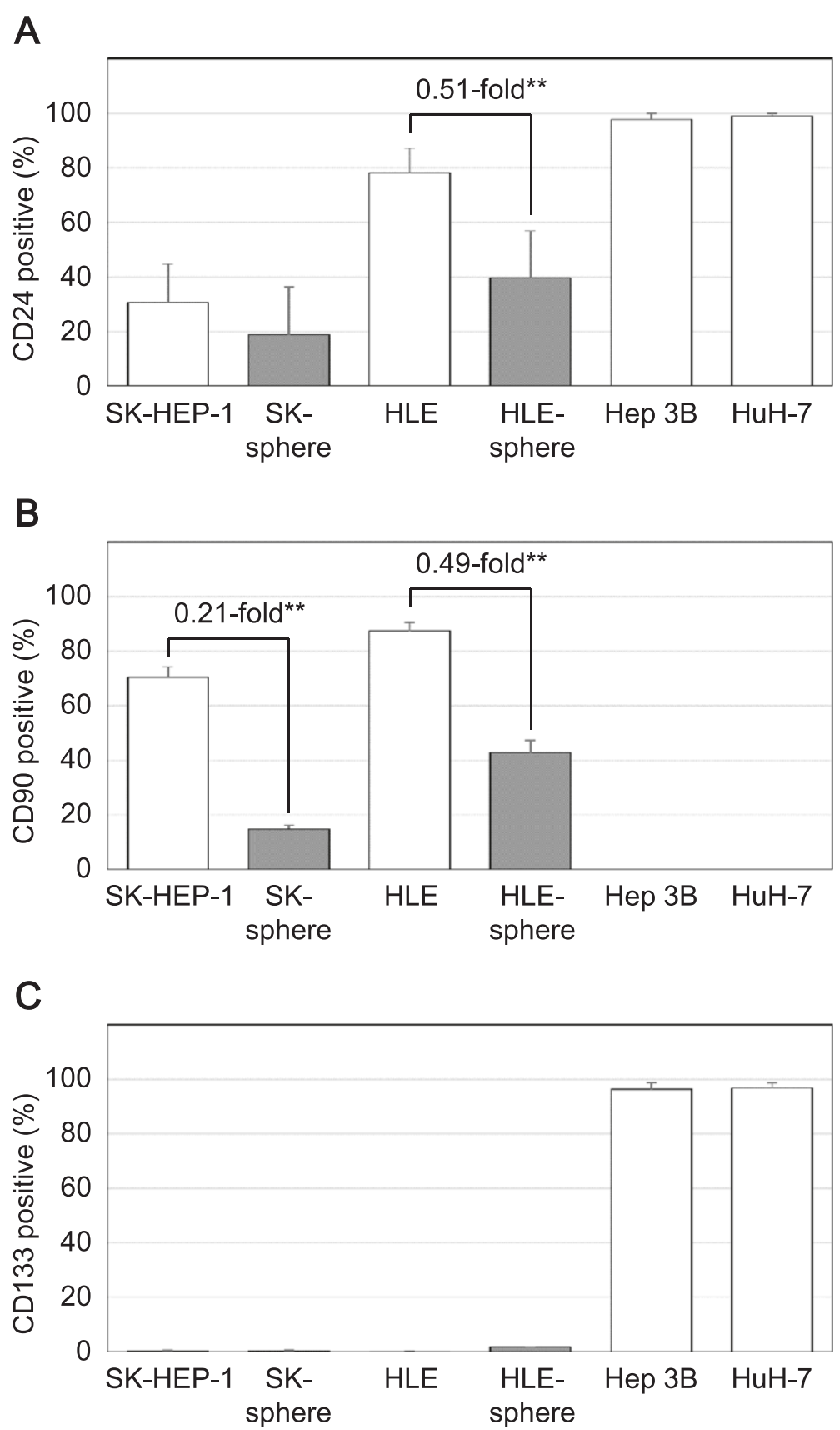

Figure 5 Flow cytometric analysis of CD24, CD90, and CD133 expressions. Cells were stained with APC-conjugated anti-CD24 antibody ( $A$ ) FITC-conjugated anti-CD90 antibody (B), and PE-conjugated anti-CD133 antibody $(\boldsymbol{C})$ and then separated with a flow cytometer. Sphere cells showed a decreased population of CD24 and CD90 positive cells than their parental cells. SK-HEP-1, HLE, and these derivative cells were negative for CD133.

showed approximately 3.0-fold higher ABCG2 mRNA levels compared to SK cells $(P<0.05$, Figure 8A). Similarly, protein expression levels of ABCG2 were higher in SK-sphere cells than parental cells (Figure 8B-D). On the other hand, HLE and HLE-sphere cells showed no significant difference in the ABCG2 expression (Figure 8D).

\section{Cell cycle distribution in sphere forming cells}

SK cells showed a cell cycle distribution of $64.5 \pm 3.2 \%$ at G0/G1, $13.9 \pm 4.7 \%$ at $S$, and $21.6 \pm 1.5 \%$ at $\mathrm{G} 2 / \mathrm{M}$ phases. In contrast, SK-sphere cells showed a cell cycle distribution of $87.8 \pm 7.8 \%$ at $\mathrm{G0} / \mathrm{G} 1,2.5 \pm 1.9 \%$ at $\mathrm{S}$, and $9.7 \pm$ $5.9 \%$ at G2/M phases (Figure 9A and B). HLE-sphere cells 


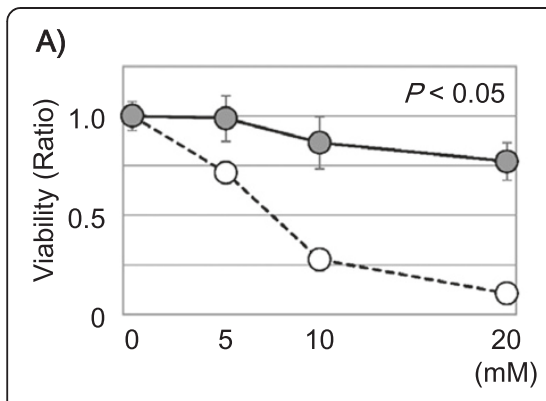

D)

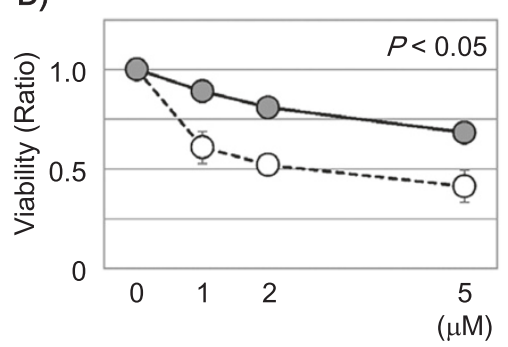

G)

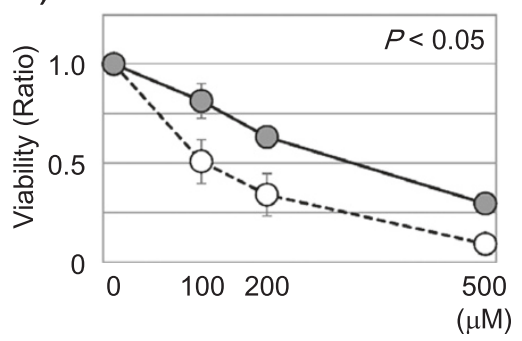

B)

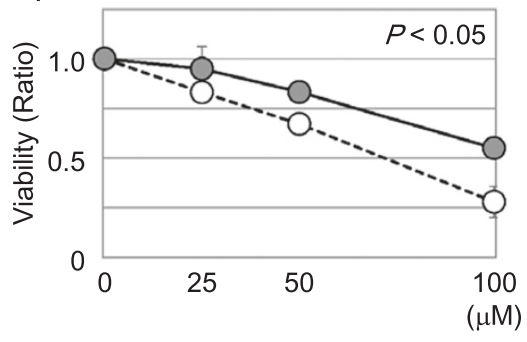

E)

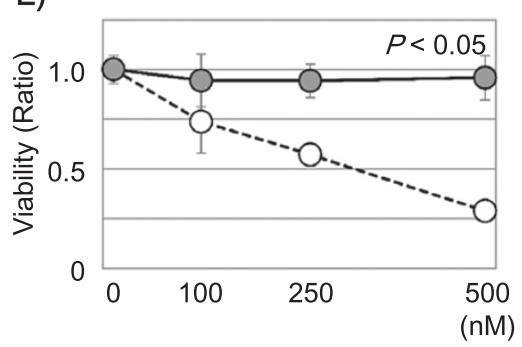

H)

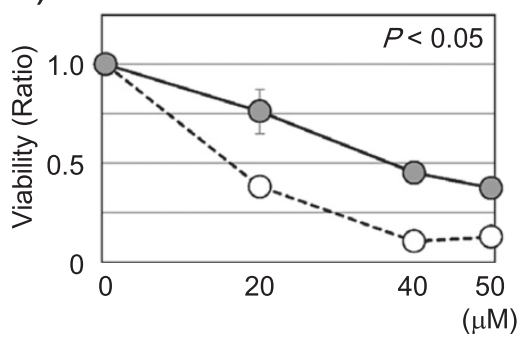

C)

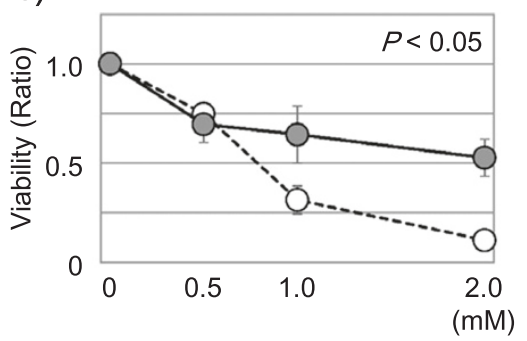

F)

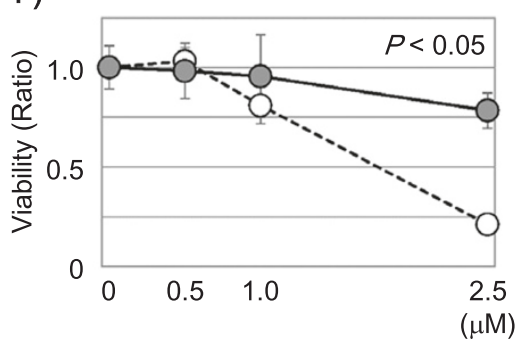

l)

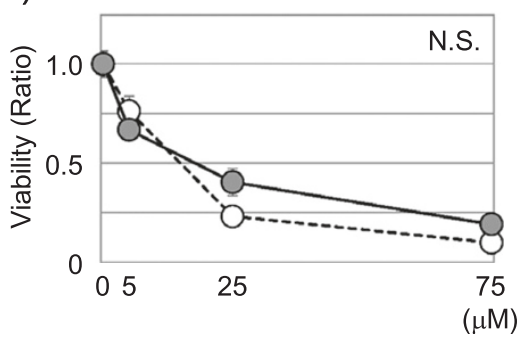

Figure 6 Susceptibility of SK-HEP-1 derivative cells to anti-cancer drugs. Cells were subjected to an MTS assay to evaluate the viability of SK-HEP-1 (open circles) and SK-sphere (closed circles) cells in the presence of anti-cancer drugs ( $\boldsymbol{A}$, 5-FU; $\boldsymbol{B}$, cisplatin; $\boldsymbol{C}$, carboplatin, $\boldsymbol{D}$, doxorubicin; $\boldsymbol{E}$, docetaxel; $\boldsymbol{F}$, SAHA; $\boldsymbol{G}$, irinotecan; $\boldsymbol{H}$, sunitinib; and $\boldsymbol{I}$, sorafenib). Except for sorafenib, SK-sphere cells showed higher viability in the presence of the tested anti-cancer drugs. $P$ values were calculated with repeated-measures ANCOVA.

also showed increased proportion of G0/G1 phase compared to HLE cells (Figure 9C and D). Furthermore, mRNA expression levels of $P 21$, which encode the cyclindependent kinase inhibitor 1, were increased in SK-sphere (2.0-fold, $P<0.05)$ and HLE-sphere $(2.2$-fold, $P<0.05)$ cells compared to parental cells (Figure 9E).

\section{HIF1a expression and ROS levels}

We examined mRNA levels of HIF1A encoding hypoxia inducible factor 1 , alpha subunit (HIF1 $\alpha)$ and intracellular ROS levels using semi-qRT-PCR analysis and a fluorogenic probe that is activated by ROS, respectively. SemiqRT-PCR showed that the mRNA levels of HIF1A were approximately 2.4-fold higher in SK-sphere cells than parental cells $(P<0.05$, Figure 10A). Furthermore, lower ROS activity was observed in SK-sphere cells than in parental cells (approximately 0.1 -fold, $P<0.05$, Figure 10B). HLE cells also showed that the higher HIF1A expression and lower ROS production in sphere-formed cells than its parental cells (Figure 10). Those results indicated that sphere cells from both SK and HLE cells had elevated antioxidant potential.

\section{Discussion}

In the present study, we developed a novel method using NSF-1-supplemented medium to induce sphere cells from an SK cell line, which was derived from a human poorly differentiated HCC. HLE cells, which were derived from an undifferentiated HCC, also formed sphere-like cells. On the other hand, using the same culture method, no sphere cells were derived from Hep 3B and HuH-7 cells, which are both derived from well-differentiated HCC. The SK-sphere cells showed higher expression levels of CSC markers and higher anti-cancer drug resistance compared to parental SK cells. Furthermore, we also observed upregulation of ABCG2 expression, cell cycle arrest at G0/ G1, overexpression of HIF1 $\alpha$, and decreased ROS production in SK-sphere cells compared to parental SK cells.

Recently, sphere formation has been thought to be an effective method of enrichment or induction of stem cell-like 


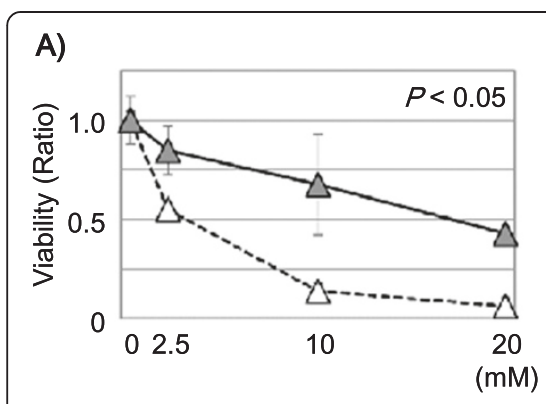

D)

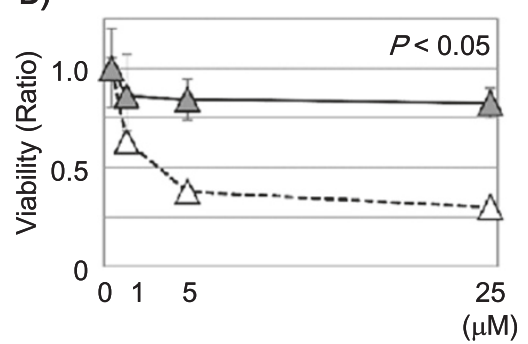

G)

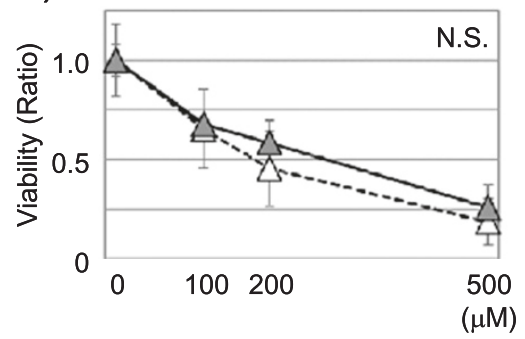

B)

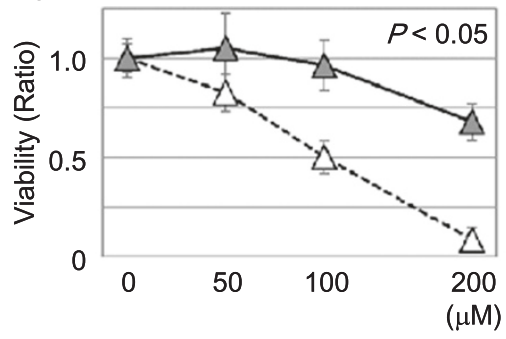

E)

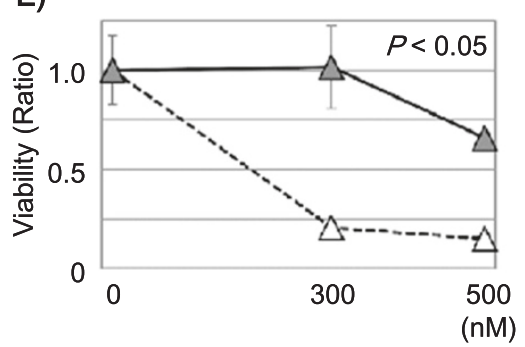

H)

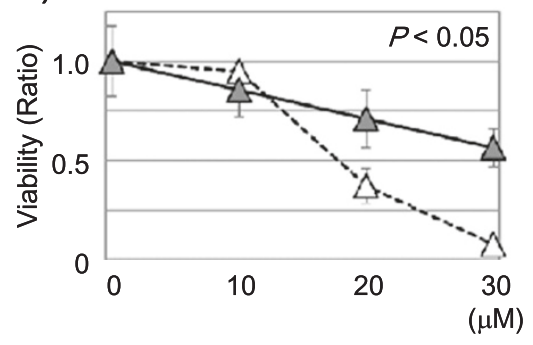

C)

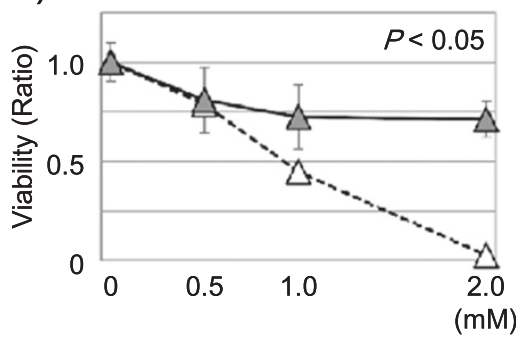

F)

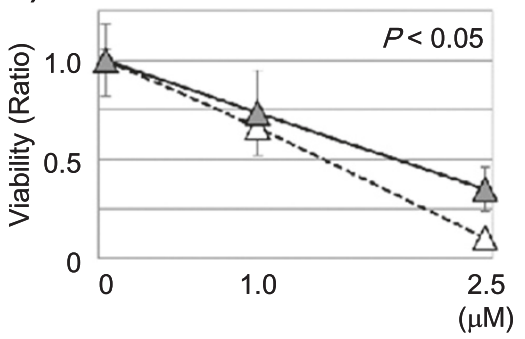

l)

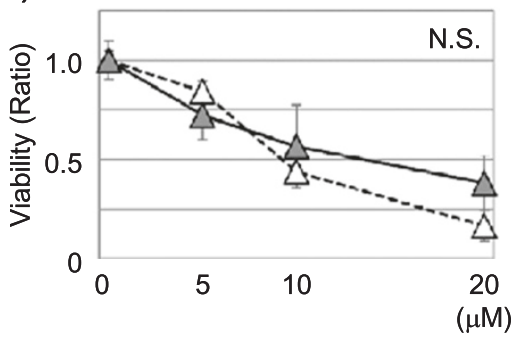

Figure 7 Susceptibility of HLE derivative cells to anti-cancer drugs. Cells were subjected to an MTS assay to evaluate the viability of HLE (open triangles) and HLE-sphere (closed triangles) cells in the presence of anti-cancer drugs $(\boldsymbol{A}, 5$-FU; $\boldsymbol{B}$, cisplatin; $\boldsymbol{C}$, carboplatin, $\boldsymbol{D}$, doxorubicin; $\boldsymbol{E}$, docetaxel; $\boldsymbol{F}$, SAHA; $\boldsymbol{G}$, irinotecan; $\boldsymbol{H}$, sunitinib; and $\boldsymbol{I}$, sorafenib). $P$ values were calculated with repeated-measures ANCOVA.

cells from various types of cancers $[16,17,27]$. The advantage of induction and enrichment of CSCs is that cell sorting, which damages cells, is not required. Usually, sphere formation is done with serum-free medium supplemented with bFGF and EGF $[15,17,28,29]$. In addition to bFGF and EGF, we added NSF-1, which is a key factor for SK-sphere induction (Figure 2). In our condition, numerous cancer stem-like sphere cells were obtained easily. Several studies have used B27 and N2 supplements instead of NSF-1 to form sphere cells [15-17,27,29]. NSF-1-containing medium was more efficient than B27-supplemented medium for inducing sphere cells (data not shown). Furthermore, our induction system could generate a sphere from a single cell (Figure 1).

Interestingly, in our condition, sphere cells were induced from the poorly or un-differentiated HCC-derived cell lines, SK and HLE, but not from the well-differentiated HCCderived cell lines, Hep 3B and HuH-7. The SK-spheres we obtained showed increased expression of stemness markers and CD44 isoform expression (Figures 3 and 4). NANOG and LIN28, which are induced pluripotent stem cellrelated genes and master transcription factors essential for maintaining stem cell phenotypes [30,31], and high ALDH activity have been found in stem cell populations in various types of cancers [32,33]. CD44 variant isoforms have been identified as markers for CSCs and metastatic behavior in several solid cancers $[7,34]$. On the contrary, CD24 expression was down-regulated in sphere cells (Figure 5). Down-regulation of CD24 was observed in CSCs of breast cancer [35]. However, a well-known CSC marker for HCC, CD133 [8,9,13], was not expressed in SK- and HLEspheres (Figure 5). Moreover, the strongly CD133-positive cell lines, Hep 3B and $\mathrm{HuH}-7$, did not form spheres. Previous studies have shown that well-differentiated hepatoma-derived cell lines contain more CSCs than poorly differentiated hepatoma-derived cell lines [22]. These findings suggest the existence of a difference between CSCs at the top of the hierarchy model that are responsible for primary cancer initiation [18] and CSCs derived from progressed cancer with plasticity [23]. Such contextual signals within the cancer microenvironment 


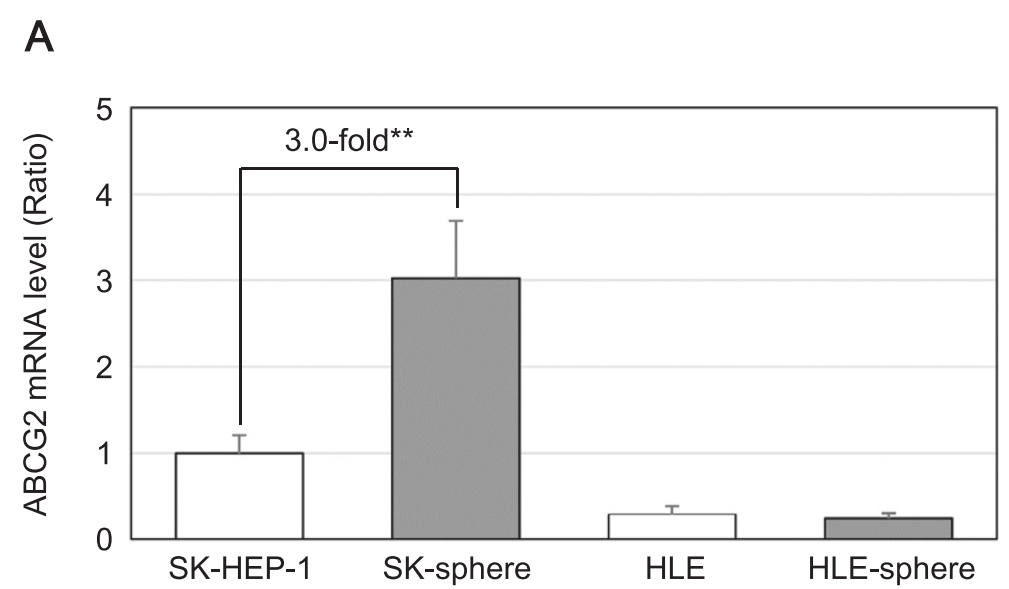

B

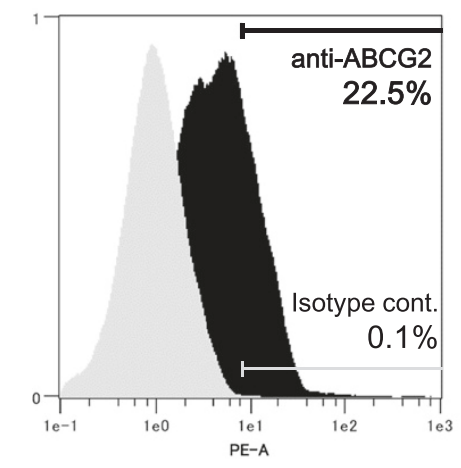

C

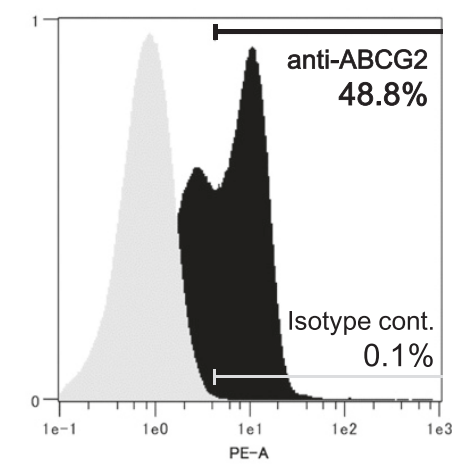

D

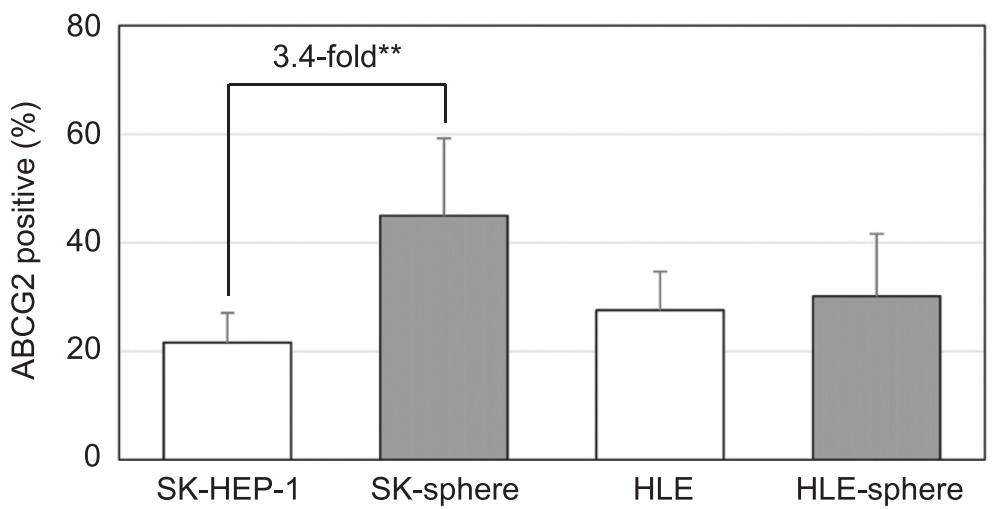

Figure 8 Expression levels of $\mathbf{A B C G}$. The expression levels of ABCG2 mRNA $(\boldsymbol{A})$ and protein $(\boldsymbol{B}$ to $\boldsymbol{D})$ were examined with semi-quantitative RT-PCR and flow cytometry, respectively. $\boldsymbol{B}$ and $\boldsymbol{C}$, representative flow cytometry histograms of SK-HEP-1 and SK-sphere cells, respectively. Black and gray histograms represent cells stained with PE-conjugated anti-ABCG2 and isotype control antibodies, respectively. $\boldsymbol{D}$, bar-chart summarized from independent flow cytometric experiments. ${ }^{* *} P<0.05$ with the Mann-Whitney U-test.

and EMT contribute to the plasticity of cancer, which involves transformation to cancer stem-like cells [36]. Indeed, expression of the mesenchymal marker vimentin was up-regulated in SK-sphere cells (data not shown).

Many studies have indicated that CSCs play a critical role in chemoresistance $[9,37,38]$. Our induced cancer stem-like sphere cells, SK-spheres and HLE-spheres, showed lower susceptibility to 5-FU, cisplatin, carboplatin, doxorubicin, docetaxel, SAHA, and sunitinib than their parental cells. One well-known mechanism of chemoresistance is up-regulation of $\mathrm{ABC}$ transporters, which mediate efflux of the anti-cancer drugs [37-39]; expression of one $A B C$ transporter, ABCG2, was up-regulated in SK-sphere cells (Figure 8). However, HLE-sphere and HLE cells showed no 


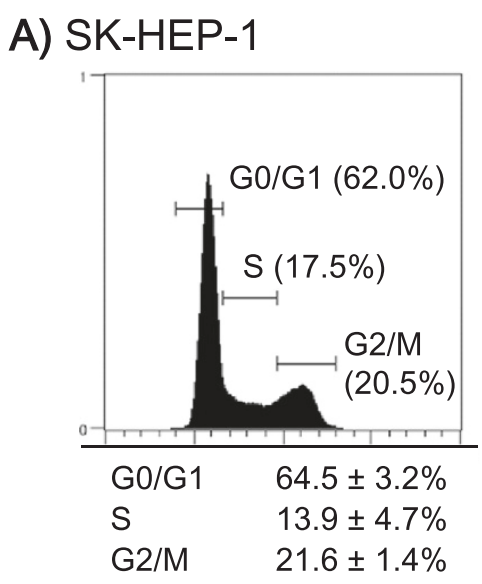

\section{C) HLE}

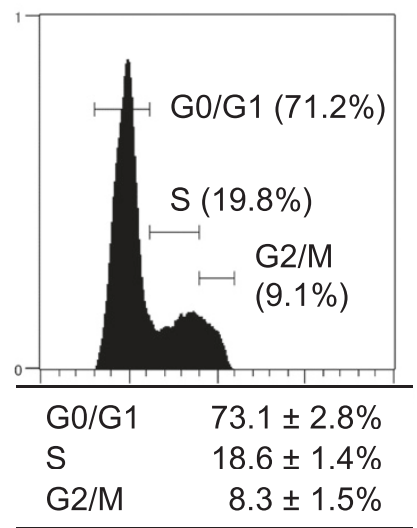

B) SK-sphere

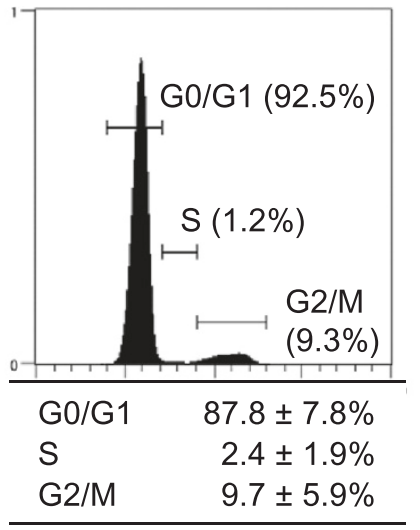

D) HLE-sphere

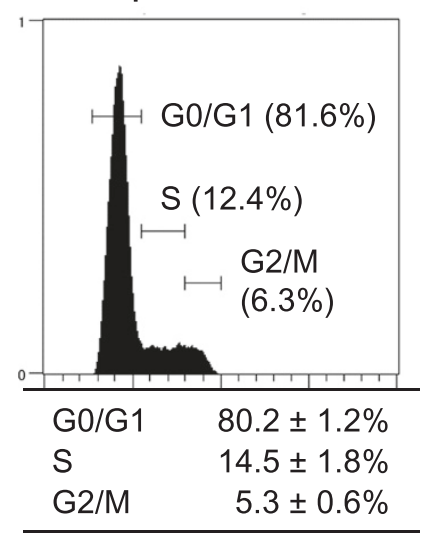

E

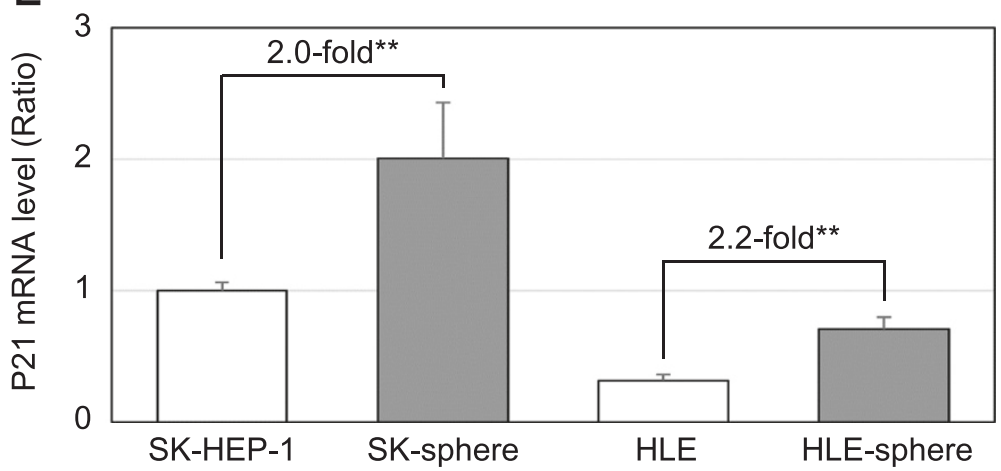

Figure 9 Cell cycle analysis. Cell cycle distribution of SK-HEP-1 $(\boldsymbol{A})$, SK-sphere $(\boldsymbol{B}), \mathrm{HLE}(\boldsymbol{C})$, and HLE-sphere $(\boldsymbol{D})$ cells, respectively. DNA content of the cells was analyzed as described in Methods. Each panel ( $\boldsymbol{A}$ to $\boldsymbol{D})$ shows a representative histogram (upper) and a summary table (lower). $\boldsymbol{E}$, The mRNA levels of P21 were measured with semi-quantitative RT-PCR. ${ }^{* *} P<0.05$ with the Mann-Whitney $U$-test.

significant difference about ABCG2 expression (Figure 8). CSC dormancy is also responsible for chemoresistance of CSCs [40]. SK-sphere cells were arrested at the G0/G1 phase of the cell cycle compared to parental SK cells, and the P21 mRNA level was higher in SK-sphere cells than in SK cells (Figure 9). P21 plays an important role in the transition of the cell cycle from the G0/G1 to the $S$ phase [41,42].

ROS are also important factors for chemoresistance of cancer. In SK-sphere and HLE-sphere cells, up-regulation of HIF $1 \alpha$ expression and decreased levels of ROS were observed (Figure 10). CSCs contained lower ROS levels and 


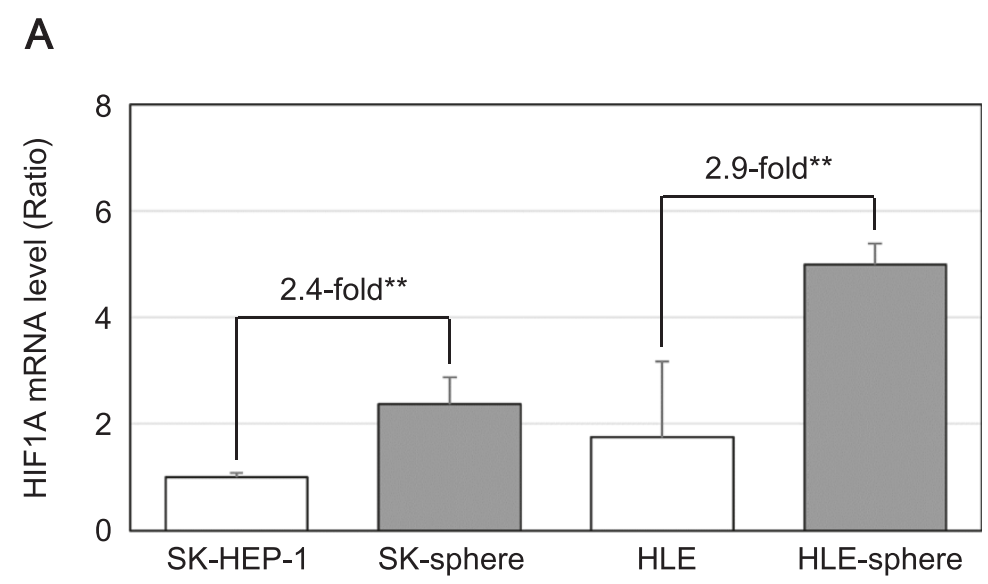

B

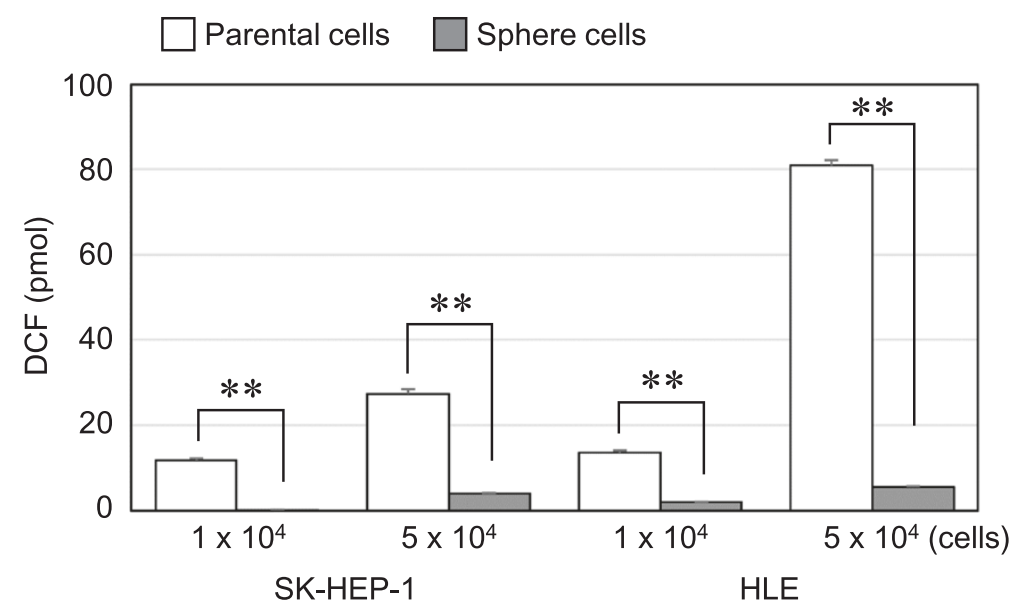

Figure 10 HIF1A mRNA and ROS levels. The MRNA level of HIF1A $(\boldsymbol{A})$ and the intracellular ROS level $(\boldsymbol{B})$ were measured as described in Methods. ${ }^{*} P<0.05$ with the Mann-Whitney $U$-test.

developed less DNA damage compared with non-CSCs. HIF- $1 \alpha$, which is a member of the major family of transcription factors that are activated by hypoxia, is an important contributor to reduction of ROS production $[28,43,44]$. Furthermore, SK-sphere and HLE-sphere cells had more cells that were positive for the $\mathrm{CD} 44$ variant isoform (Figure 4), which stabilizes the $\mathrm{xCT}$ transporter and enhance antioxidant synthesis [45].

Among the anti-cancer drugs we tested, only sorafenib exerted an anti-cancer effect on both sphere cells and parental cells (Figures 6 and 7). Although both sorafenib and sunitinib are multi-targeted receptor tyrosine kinase inhibitor, sorafenib inhibits RAS/RAF/MAPK signaling, and treatment of patients with advanced HCC with sorafenib provides longer overall survival than sunitinib [46]. Therefore, sorafenib may be useful against both HCC and CSCs from HCC.

Although HLE-sphere cells as well as SK-sphere cells showed significantly increased resistance to several anti- cancer drugs and antioxidant potentials compared to parental cells, sphere cells from HLE cells seem to be cells bearing cancer stem-like properties with incompleteness in morphology, stemness marker, and ABCG2 expressions.

\section{Conclusion}

In conclusion, we developed a novel method for induction of cancer stem-like chemoresistant sphere cells from cell lines derived from de-differentiated $\mathrm{HCC}$ involving shortterm cultivation.

\section{Additional files}

Additional file 1: Table S1. Primers and hydrolysis probes used in this study.

Additional file 2: Figure S1. Sphere induction from HCC cell lines. A and B, HLE cells cultivated in the sphere induction medium for 4 days. There was floating sphere cells and adherent cells. Dissociated SK-sphere and 
$\mathrm{HLE}$-sphere cells were re-cultivated in the induction medium for 7 days ( $C$ and D, photographs of passage 3 ) and normal medium containing FBS ( $\mathrm{E}$ and $\mathrm{F}$ ). Hep3B (G) and $\mathrm{HuH}-7$ ( $\mathrm{H}$ ) cells in the same sphere induction medium, but there was no spheroids nor floating cells.

Additional file 3: Figure S2. ALDH expression and activity. The mRNA levels of ALDH1A1 were measured with semi-quantitative RT-PCR and represented as the ratio to levels in SK-HEP-1 cells (A). ${ }^{*} P<0.05$ with the Mann-Whitney U-test. The ALDEFLUOR kit (STEMCELL Technologies, Durham, NC) was used to analyze the ALDH enzymatic activity in a population of cells. Band C, SK-HEP-1 and SK-sphere cells were suspended in ALDEFLUOR assay buffer containing ALDH substrate and incubated for $40 \mathrm{~min}$ at $37^{\circ} \mathrm{C}$. D and $\mathrm{E}$, as a negative control, an aliquot of SK-HEP-1 and SK-sphere cells was treated with $50 \mathrm{mM}$ diethylaminobenzaldehyde (DEAB), a specific ALDH inhibitor.

\section{Competing interests}

The authors declare that they have no competing interests.

\section{Authors' contribution}

RT designed the experiments and the paper. Acquisition of data were accomplished by NH, YW, and RT. Interpretation of data was done by RT, NH, $\mathrm{KY}, \mathrm{SH}$, and MO. NH and RT wrote the paper. All authors read and approved the final manuscript.

\section{Acknowledgements}

We thank Moeko Inoue and Akiko Sano for their assistance with this project. This work was partly supported by JSPS KAKENHI Grant Number 25861192 and 24659610

Received: 8 April 2014 Accepted: 17 September 2014 Published: 27 September 2014

\section{References}

1. Forner A, Llovet JM, Bruix J: Hepatocellular carcinoma. Lancet 2012 379:245-255.

2. Tung-Ping PR, Fan ST, Wong J: Risk factors, prevention, and management of postoperative recurrence after resection of hepatocellular carcinoma. Ann Surg 2000, 232:10-24.

3. Chang CH, Chau GY, Lui WY, Tsay SH, King KL, Wu CW: Long-term results of hepatic resection for hepatocellular carcinoma originating from the noncirrhotic liver. Arch Surg 2004, 139:320-325.

4. Clarke MF, Dick JE, Dirks PB, Eaves CJ, Jamieson CH, Jones DL, Visvader J, Weissman IL, Wahl GM: Cancer stem cells-perspectives on current status and future directions: AACR Workshop on cancer stem cells. Cancer Res 2006, 66:9339-9344.

5. Singh SK, Hawkins C, Clarke ID, Squire JA, Bayani J, Hide T, Henkelman RM, Cusimano MD, Dirks PB: Identification of human brain tumour initiating cells. Nature 2004, 432:396-401.

6. Ho MM, Ng AV, Lam S, Hung JY: Side population in human lung cancer cell lines and tumors is enriched with stem-like cancer cells. Cancer Res 2007, 67:4827-4833.

7. Endo K, Terada T: Protein expression of cd44 (standard and variant isoforms) in hepatocellular carcinoma: relationships with tumor grade, clinicopathologic parameters, p53 expression, and patient survival. J Hepatol 2000, 32:78-84.

8. Ma S, Chan KW, Hu L, Lee TK, Wo JY, Ng IO, Zheng BJ, Guan XY: Identification and characterization of tumorigenic liver cancer stem/ progenitor cells. Gastroenterology 2007, 132:2542-2556.

9. Ma S, Lee TK, Zheng BJ, Chan KW, Guan XY: CD133+ HCC cancer stem cells confer chemoresistance by preferential expression of the akt/pkb survival pathway. Oncogene 2008, 27:1749-1758.

10. Yang ZF, Ho DW, Ng MN, Lau CK, Yu WC, Ngai P, Chu PW, Lam CT, Poon RT, Fan ST: Significance of CD90+ cancer stem cells in human liver cancer. Cancer Cell 2008, 13:153-166.

11. Yang W, Yan HX, Chen L, Liu Q, He YQ, Yu LX, Zhang SH, Huang DD, Tang L, Kong XN, Chen C, Liu SQ, Wu MC, Wang HY: Wnt/beta-catenin signaling contributes to activation of normal and tumorigenic liver progenitor cells. Cancer Res 2008, 68:4287-4295.

12. Kimura $\mathrm{O}$, Takahashi $\mathrm{T}$, Ishii $\mathrm{N}$, Inoue $\mathrm{Y}$, Ueno $\mathrm{Y}$, Kogure $\mathrm{T}$, Fukushima $\mathrm{K}$ Shiina M, Yamagiwa Y, Kondo Y, Inoue J, Kakazu E, Iwasaki T, Kawagishi N,
Shimosegawa T, Sugamura K: Characterization of the epithelial cell adhesion molecule (EPCAM) + cell population in hepatocellular carcinoma cell lines. Cancer Sci 2010, 101:2145-2155.

13. Fan L, He F, Liu H, Zhu J, Liu Y, Yin Z, Wang L, Guo Y, Wang Z, Yan Q, Huang G: CD133: a potential indicator for differentiation and prognosis of human cholangiocarcinoma. BMC Cancer 2011, 11:320.

14. Kim HM, Haraguchi N, Ishii H, Ohkuma M, Okano M, Mimori K, Eguchi H, Yamamoto H, Nagano H, Sekimoto M, Doki Y, Mori M: Increased CD13 expression reduces reactive oxygen species, promoting survival of liver cancer stem cells via an epithelial-mesenchymal transition-like phenomenon. Ann Surg Oncol 2012, 3:539-548.

15. Shen G, Shen F, Shi Z, Liu W, Hu W, Zheng X, Wen L, Yang X: Identification of cancer stem-like cells in the C6 glioma cell line and the limitation of current identification methods. In Vitro Cell Dev Biol Anim 2008, 44:280-289.

16. Yu SC, Ping YF, Yi L, Zhou ZH, Chen JH, Yao XH, Gao L, Wang JM, Bian XW: Isolation and characterization of cancer stem cells from a human glioblastoma cell line U87. Cancer Lett 2008, 265:124-134.

17. Cao L, Zhou Y, Zhai B, Liao J, Xu W, Zhang R, Li J, Zhang Y, Chen L, Qian H, Wu M, Yin Z: Sphere-forming cell subpopulations with cancer stem cell properties in human hepatoma cell lines. BMC Gastroenterol 2011, 11:71.

18. O'Brien CA, Kreso A, Jamieson CH: Cancer stem cells and self-renewal. Clin Cancer Res 2010, 16:3113-3120.

19. Chiba T, Kita K, Zheng YW, Yokosuka O, Saisho H, Iwama A, Nakauchi H, Taniguchi H: Side population purified from hepatocellular carcinoma cells harbors cancer stem cell-like properties. Hepatology 2006, 44:240-251.

20. Harris MA, Yang H, Low BE, Mukherjee J, Guha A, Bronson RT, Shultz LD, Israel MA, Yun K: Cancer stem cells are enriched in the side population cells in a mouse model of glioma. Cancer Res 2008, 68:10051-10059.

21. Yamashita T, Ji J, Budhu A, Forgues M, Yang W, Wang HY, Jia H, Ye Q, Qin LX, Wauthier E, Reid LM, Minato H, Honda M, Kaneko S, Tang ZY, Wang XW: EpCAM-positive hepatocellular carcinoma cells are tumor-initiating cells with stem/progenitor cell. Gastroenterology 2009, 136:1012-1024.

22. Chen X, Lingala S, Khoobyari S, Nolta J, Zern MA, Wu J: Epithelial mesenchymal transition and hedgehog signaling activation are associated with chemoresistance and invasion of hepatoma subpopulations. J Hepatol 2011, 55:838-845.

23. Mani SA, Guo W, Liao MJ, Eaton EN, Ayyanan A, Zhou AY, Brooks M, Reinhard F, Zhang CC, Shipitsin M, Campbell LL, Polyak K, Brisken C, Yang J, Weinberg RA: The epithelial-mesenchymal transition generates cells with properties of stem cells. Cell 2008, 133:704-715.

24. Chiou SH, Yu CC, Huang CY, Lin SC, Liu CJ, Tsai TH, Chou SH, Chien CS, $\mathrm{Ku} \mathrm{HH}$, Lo JF: Positive correlations of Oct-4 and Nanog in oral cancer stem-like cells and high-grade oral squamous cell carcinoma. Clin Cancer Res 2008, 14:4085-4095.

25. Thon N, Damianoff K, Hegermann J, Grau S, Krebs B, Schnell O, Tonn JC, Goldbrunner R: Presence of pluripotent CD133+ cells correlates with malignancy of gliomas. Mol Cell Neurosci 2010, 43:51-59.

26. Tsunedomi R, lizuka N, Tamesa T, Sakamoto K, Hamaguchi T, Somura H, Yamada M, Oka M: Decreased ID2 promotes metastatic potentials of hepatocellular carcinoma by altering secretion of vascular endothelial growth factor. Clin Cancer Res 2008, 14:1025-1031.

27. Zhong Y, Guan K, Guo S, Zhou C, Wang D, Ma W, Zhang Y, Li C, Zhang S: Spheres derived from the human SK-RC-42 renal cell carcinoma cell line are enriched in cancer stem cells. Cancer Lett 2010, 299:150-160.

28. Bao S, Wu Q, McLendon RE, Hao Y, Shi Q, Hjelmeland AB, Dewhirst MW, Bigner DD, Rich JN: Glioma stem cells promote radio-resistance by preferential activation of the DNA damage response. Nature 2006, 444:756-760.

29. Lee J, Kotliarova S, Kotliarov Y, Li A, Su Q, Donin NM, Pastorino S, Purow BW, Christopher N, Zhang W, Park JK, Fine HA: Tumor stem cells derived from glioblastomas cultured in bFGF and EGF more closely mirror the phenotype and genotype of primary tumors than do serum-cultured cell lines. Cancer Cell 2006, 9:391-403.

30. Chambers I, Colby D, Robertson M, Nichols J, Lee S, Tweedie S, Smith A Functional expression cloning of Nanog, a pluripotency sustaining factor in embryonic stem cells. Cell 2003, 113:643-655.

31. Yang DH, Moss EG: Temporally regulated expression of Lin-28 in diverse tissues of the developing mouse. Gene Expr Patterns 2003, 3:719-726.

32. Ma S, Chan KW, Lee TK, Tang KH, Wo JY, Zheng BJ, Guan XY: Aldehyde dehydrogenase discriminates the CD133 liver cancer stem cell populations. Mol Cancer Res 2008, 6:1146-1153. 
33. Ma I, Allan AL: The role of human aldehyde dehydrogenase in normal and cancer stem cells. Stem Cell Rev 2011, 7:292-306.

34. Gao C, Guo H, Downey L, Marroquin C, Wei J, Kuo PC: Osteopontin-dependent CD44v6 expression and cell adhesion in HepG2 cells. Carcinogenesis 2003, 24:1871-1878.

35. Phillips TM, McBride WH, Pajonk F: The response of CD24(-/low)/CD44+ breast cancer-initiating cells to radiation. J Natl Cancer Inst 2006, 98:1777-1785.

36. Scheel C, Weinberg RA: Phenotypic Plasticity and Epithelial-Mesenchymal Transitions in Cancer - and Normal Stem Cells? Int I Cancer 2011, 129:2310-2314.

37. Szakacs G, Paterson JK, Ludwig JA, Booth-Genthe C, Gottesman MM: Targeting multidrug resistance in cancer. Nat Rev Drug Discov 2006, 5:219-234.

38. Sukowati CH, Rosso N, Crocè LS, Tiribelli C: Hepatic cancer stem cells and drug resistance: Relevance in targeted therapies for hepatocellular carcinoma. World J Hepatol 2010, 2:114-126.

39. Gillet JP, Gottesman MM: Advances in themolecular detection of ABC transporters involved in multidrug resistance in cancer. Curr Pharm Biotechnol 2011, 12:686-692.

40. Gottesman MM: Mechanisms of cancer drug resistance. Annu Rev Med 2002, 53:615-627.

41. Sherr CJ, Roberts JM: CDK inhibitors: positive and negative regulators of G1-phase progression. Genes Dev 1999, 13:1501-1512.

42. Coqueret O: New roles for p21 and p27 cell-cycle inhibitors: a function for each cell compartment? Trends Cell Biol 2003, 13:65-70.

43. Semenza GL: HIF-1 and tumor progression: pathophysiology and therapeutics. Trends Mol Med 2002, 8:62-67.

44. Rohwer N, Cramer T: HIFs as central regulators of gastric cancer pathogenesis. Cancer Biol Ther 2010, 10:383-385.

45. Nagano O, Okazaki S, Saya H: Redox regulation in stem-like cancer cells by CD44 variant isoforms. Oncogene 2013, 32:5191-5198.

46. Chang A, Kang Y, Lin D, Park J, Kudo M, Qin S, Omata M, Pitman Lowenthal SW, Lanzalone S, Yang L, Lechuga M, Raymond E: Phase III trial of sunitinib (Su) versus sorafenib (So) in advanced hepatocellular carcinoma (HCC). J Clin Oncol 2011, 29(suppl):256s. Abstract 4000.

doi:10.1186/1471-2407-14-722

Cite this article as: Hashimoto et al:: Cancer stem-like sphere cells induced from de-differentiated hepatocellular carcinoma-derived cell lines possess the resistance to anti-cancer drugs. BMC Cancer 2014 14:722.

\section{Submit your next manuscript to BioMed Central and take full advantage of:}

- Convenient online submission

- Thorough peer review

- No space constraints or color figure charges

- Immediate publication on acceptance

- Inclusion in PubMed, CAS, Scopus and Google Scholar

- Research which is freely available for redistribution 